\title{
ACURACIDADE DE INFORMAÇÃO A PARTIR DA REDEFINIÇÃO DO LAYOUT DE ESTOQUE EM UMA EMPRESA DO RAMO DE HIGIENE E LIMPEZA
}

\author{
Tiago Henrique de Oliveira Silva - Faculdade de Tecnologia de Guaratinguetá \\ tiagosidspfc@gmail.com \\ Mônica Holanda Santos \\ monica.holanda.santos@outlook.com \\ André Ricardo Soares Amarante - Faculdade de Tecnologia de Guaratinguetá \\ andre.amarante@fatec.sp.gov.br
}

\section{Resumo}

As empresas precisam estar bem preparadas, do ponto de vista da gestão da produção, devido à dinâmica que o mercado vem impondo, aliada à mudança no comportamento do consumidor, percebida ao longo dos últimos anos. A presente pesquisa apresenta um estudo que envolve a identificação e a análise dos atuais processos de uma empresa de produtos de limpeza, e apresentação de um plano de ação de maneira a reduzir as oportunidades de melhorias identificadas em seus processos produtivos. Para 0 desenvolvimento da pesquisa foram utilizadas pesquisas bibliográficas e pesquisas documentais; para a análise dos processos produtivos utilizou-se a Matriz de Gravidade, Urgência e Tendência e o Diagrama de Ishikawa. Percebeu-se uma oportunidade ótima, no momento em que temos de um lado a empresa em questão, que tem uma série de oportunidades de melhoria em seu processo produtivo; por outro lado os alunos de uma Faculdade de Tecnologia, que tem a oportunidade de aplicar os conceitos vistos em sala de aula. O material produzido, à partir da pesquisa realizada, demonstra que ambos os lados se beneficiaram, se forma significativa, do resultado desta pesquisa.

Palavras-chave: Gestão da Produção; Melhorias; Acuracidade. 


\begin{abstract}
Companies need to be well-prepared from the point of view of production management, due to the dynamics that the market is imposing, coupled with the change in consumer behavior, perceived over the last few years. The present research presents a study that involves the identification and analysis of a company's current processes of cleaning products and presentation of a plan of action in order to reduce the opportunities for improvements identified in its productive processes. For the development of the research were used bibliographical research and documentary research; For the analysis of the productive processes was used the Gravity, Urgency and Trend Matrix and the Ishikawa Diagram. It was perceived a great opportunity, at the moment in which we have of one side the company in question, that has a series of opportunities of improvement in its productive process; On the other hand the students of a Faculty of Technology, who have the opportunity to apply the concepts seen in the classroom. The material produced, based on the research, shows that both sides benefited, if significant, from the result of this research.
\end{abstract}

Keywords: Production Management; Improvements; Accuracy

\title{
1 Introdução
}

Atualmente observa-se, cada vez mais que as organizações estão preocupadas com seu crescimento em meio ao mercado competitivo. Por esta razão, a busca por métodos que melhorem a gestão é de extrema importância para que se possa alcançar metas e atingir objetivos. Desta forma, a interdisciplinaridade de conceitos e também os processos reais que uma organização exerce diariamente se complementam tornando-se possível a visão cada vez mais esquematizada de forma a sugerir e aperfeiçoar seus métodos, de acordo com a necessidade de cada empresa.

Desta forma, a Gestão da Produção se mostra como um conceito primordial a qualquer organização, pois alinha as estratégias à execução dos processos, visando sempre o controle e aperfeiçoamento de resultados.

Ademais, a Tecnologia da Informação se faz necessária para armazenar e gerir informações que auxiliem no processo de decisão, através de sistemas que se 
adaptem a realidade e necessidade individual que cada empresa exerce, conectando todas as atividades em processos mais ágeis para a tomada de decisão.

O presente trabalho consiste em elaborar um plano de melhorias na forma de um EAP dentro dos processos de produção de uma empresa real, situada em Guaratinguetá, interior do Estado de São Paulo, envolvendo Gestão da Produção, para desta forma padronizar os processos e buscar por melhorias dentro do atual cenário da organização.

A Estrutura Analítica do Projeto (EAP) irá ajudar a estruturar o plano de ação e identificar as atividades que serão executadas no projeto. "Este é o processo necessário para identificar as atividades específicas que precisam ser realizadas para produzir as várias entregas do projeto" (Bruzzi; 2008).

Com a finalidade de identificar oportunidades de melhoria na produção, foram realizadas diversas análises no layout de fabricação e no histórico de dados fornecidos, a fim de estudar a situação atual dos processos e sugerir melhorias, bem como estratégias, de implantação através de indicação de ferramentas da qualidade para maior administração de produtos. Tem-se como objetivo geral estudar os processos produtivos de uma empresa de segmento industrial no ramo químico e propor melhorias. Como objetivos específicos: levantar pesquisas bibliográficas; observar o processo produtivo / layout da empresa; analisar e identificar possíveis oportunidades de melhoria; priorizar problemas; levantar custo de investimento e propor melhorias a partir de um plano de ação. Como métodos pode-se destacar: Visitas técnicas, pesquisas bibliográficas, documentais e a utilização de questionários semiestruturados. Para a priorização das oportunidades de melhorias (caso haja), utilizar-se-á ferramentas da qualidade como, por exemplo, a ferramenta de Gravidade, Urgência e Tendência (GUT).

\section{Contextualização da Empresa}

Empresa brasileira de pequeno porte localizada no município de Guaratinguetá, interior do Estado de São Paulo. Fundada em 2009, de origem familiar e gestão centralizadora, a empresa de segmento industrial e comercial produz soluções químicas voltadas para a limpeza e higiene. Atualmente a empresa dispõe de 4 colaboradores, um laboratório próprio e especializado para a análise, inspeção, testes 
e registro de amostras de lotes produzidos no qual segue as normas de acordo com 0 controle de qualidade e principalmente de segurança, que é obrigatório e expedido por órgãos públicos, desta forma, capaz de garantir confiabilidade no uso dos produtos.

Tratando-se de política direcionada ao marketing, nota-se que a empresa não possui, visto que boa parte de sua produção é destinada aos órgãos públicos. Porém, há utilização de marketing digital para a exibição de informações relacionadas à empresa, elementos como localização, produtos e contato em seu site exclusivo.

O local das instalações da empresa é constituído por dois pisos: superior e térreo, sendo o piso superior ocupado pelo departamento administrativo da empresa e o térreo, trata-se de um galpão o qual possui o seu espaço direcionado para estoque, produção (somente puxada) e laboratório de análises.

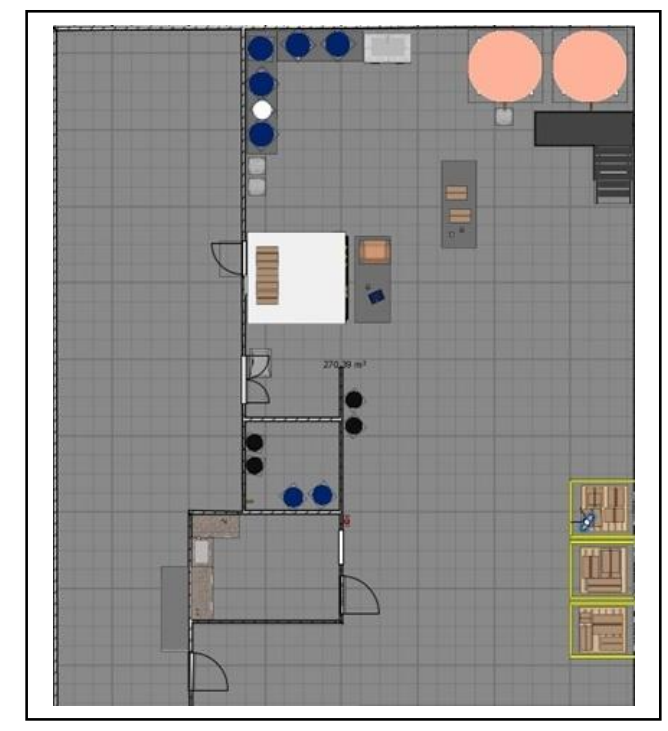

Figura 1: Térreo

Fonte: Dos próprios autores

\subsection{Produção}

O ciclo de fabricação inicia-se pelo pedido do cliente ou pelo pedido de reabastecimento do varejista. Ao receber um pedido, é verificado se o estoque de matéria prima possui capacidade para fabricação dos itens em demanda. Caso possua, a produção é iniciada o mais rápido possível (leva-se em consideração os pedidos feitos anteriormente e verificam-se as prioridades); caso não tenha, a compra 
de matéria prima é programada para o mais breve possível. Após a fabricação, os produtos são embalados e seguem para a entrega no carro próprio da empresa. A empresa possui capacidade produtiva de 10 toneladas/mês.

Atualmente, a empresa atua no mercado de segmento industrial com a fabricação de produtos para limpeza (sabonete líquido, detergente, cera multiuso, removedor e produto automotivo) e possui como principais clientes: órgãos públicos nas esferas estaduais, municipais e federais. Além disso, a empresa possui cinco fornecedores e quatro concorrentes diretos. Possui espaço interno e externo necessário para descarregamento e carregamento em seu prédio próprio de aproximadamente $250 \mathrm{~m}$ onde é dividida em: Parte térrea: recebimento, produção, estoque, embalagem, laboratório, expedição, cozinha, vestiário e garagem. Piso superior: setor administrativo.

\section{Levantamento dos Processos}

Para que houvesse a obtenção das informações referentes ao processo produtivo, tornou-se imprescindível a realização de visitas técnicas que ocorreram nos períodos entre março a maio do presente ano (2016) e que foram embasados a partir d/e questionários pré-estruturados. Gentilmente disponibilizaram-nos o gerente e um funcionário da produção para que nos acompanhassem. Cronometrou-se todo o tempo do processo produtivo da cera auto brilho a fim de quantificar o tempo perdido do funcionário ao procurar os produtos. O tempo total de produção da cera líquida é de 4 horas. Dentro destas 4 horas, cronometrou-se 30 minutos de perda de produtividade em razão de desorganização do layout e armazenamento inadequado de matéria prima, além de ausência na padronização do processo. 


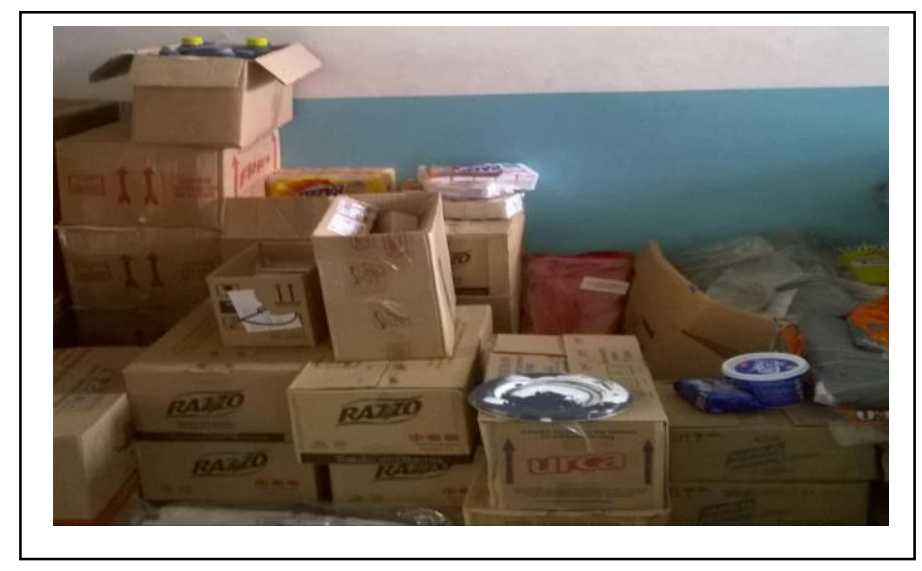

Figura 2: Atual armazenamento para expedição: acabados e revendidos Fonte: Dos próprios autores

No piso superior há um mural que contém os procedimentos dos processos de produção e que são elaborados a partir do POP (Procedimento Operacional Padrão), o qual cada produto possui, individualmente, um processo definido. Além disso, há também avisos sobre a obrigatoriedade e importância de uso dos EPIs (Equipamento de Proteção Individual). O laboratório de análises possui de forma estruturada o controle de amostras que, após lançar esses dados em planilhas, são impressas e arquivadas. Esse processo é realizado devido às fiscalizações da ANVISA, órgão regulamentador o qual a empresa deve seguir as normas de segurança e qualidade para posteriormente realizar a comercialização dos produtos. As planilhas apresentam informações como: lote interno, lote externo, nome do produto, número da amostra, localização da amostra na armazenagem, responsável pela fabricação, data de liberação, quantidade do produto e fornecedor.

Tem-se como sistema utilizado para a gestão de todos os departamentos e processos, o Gestor Total. Ele é indicado para pequenas empresas e visa controlar toda a cadeia de suprimentos da empresa, gerando relatórios que auxiliem na gestão dos mesmos. Nota-se que a empresa não utiliza todos os campos do sistema voltados à organização do estoque. Para operar, cada funcionário tem sua senha e login que permite ao gestor saber quem inseriu as informações. Os backups são feitos pelo software de forma automática e também manualmente através de um pendrive. 
A estrutura computacional da empresa é composta por três computadores e um notebook sendo um no setor de produção juntamente com uma impressora e um roteador. Os computadores possuem como sistema operacional o Windows 7 e estão interligados em rede ao qual alimenta apenas um banco de dados. Os cabos que fazem esta ligação são do tipo ethernet.

\subsection{Análise do Processo Produtivo (Cera Autobrilho)}

Tratando-se de processo produtivo, foi possível acompanhar, registrar e cronometrar a produção do produto carro chefe da empresa, a cera auto brilho. Observou-se que a produção em pequena escala é um processo manual e a fabricação da cera em específico é feita através de um equipamento que mistura todas as soluções conforme são adicionadas em um tonel ou tanque de mistura. Durante a produção observou-se que as matérias primas ficam armazenadas de forma aleatória e sem organização em um mesmo local dificultando a identificação e impossibilitando que o processo de procura seja rápido e preciso. O estoque de produtos acabados também encontram-se desorganizados em seu layout podendo resultar em perda de tempo significativa no processo.

Durante as visitas in loco foi possível identificar problemas reais tornando-se necessária a realização de uma análise mais detalhada juntamente com o responsável pela empresa para que desta forma fosse possível priorizar o problema de maior gravidade. Para identificá-lo, fez-se necessário à utilização da ferramenta da qualidade denominada Matriz GUT (Gravidade, Urgência e Tendência) que possui como principal objetivo priorizar problemas e consequentemente tratá-los. "Matriz GUT é a representação de problemas, ou riscos potenciais, através de quantificações que buscam estabelecer prioridades para abordá-los, visando minimizar os impactos" (Leusin; 2010; p.113). Os principais problemas identificados envolvem: subsistema de gestão de pessoas (treinamento e desenvolvimento), layout, gestão de tempo, medição e pesagem conforme apresenta a tabela abaixo: 


\begin{tabular}{l|c|c|c|c}
\multicolumn{1}{c|}{ Pontos de Observação } & Gravidade & Urgência & Tendência & Total \\
\hline $\begin{array}{l}\text { Desorganização dos produtos } \\
\text { acabados e revendidos }\end{array}$ & 4 & 5 & 4 & 80 \\
\hline Falta de medição nos insumos & 4 & 5 & 3 & 60 \\
\hline $\begin{array}{l}\text { Não utiliza todos os módulos } \\
\text { do SI }\end{array}$ & 3 & 4 & 3 & 36 \\
\hline Localização da balança & 4 & 3 & 2 & 24 \\
\hline $\begin{array}{l}\text { Falta de gestão de tempo ( } \\
\text { Gerente) }\end{array}$ & 4 & 3 & 3 & 24 \\
\hline $\begin{array}{l}\text { Falta de acuracidade no } \\
\text { estoque }\end{array}$ & 2 & 2 & 3 & 12 \\
\hline Falta de Treinamento & 2 & 2 & 2 & 8 \\
\hline Gestão de Tempo ( Operador ) & 1 & 1 & 1 & 1 \\
\end{tabular}

Tabela 1: Matriz GUT

Fonte: Dos próprios autores

Após a utilização da ferramenta Matriz GUT destacou-se como principal problema a questão layout o qual atualmente encontra-se visualmente desorganizado. Juntamente a esse tópico, percebeu-se também ausência de investimentos em manutenção de infraestrutura e planejamento estratégico. Isso ocasiona problemas de localização e movimentação de matéria prima (que interfere diretamente no processo produtivo) e produtos acabados, desta forma, podem-se detectar pontos de melhorias que resultem em maior agilidade e padronização na execução dos processos. Sabe-se também que, posteriormente, outros pontos de melhorias deverão ser estabelecidos, neste caso, voltados diretamente aos demais problemas mencionados. Faz-se relevante citar que os funcionários da empresa não possuem graduação ou quaisquer cursos na área. Todos os procedimentos feitos por estes são realizados a partir de leitura de todo processo produtivo o qual encontra-se sobre um balcão ao lado da balança para pesagem dos insumos. Essa leitura é realizada diariamente e os apontamentos referente a adição de determinada matéria prima são feitas a lápis no mesmo local. Os funcionários não recebem capacitação, ou seja, treinamento e desenvolvimento. Além disso, não há medidas e pesagens exatas dos insumos devido à ausência de marcadores precisos, inclusive, não há reservatório de água, o que pode gerar grandes problemas no processo produtivo devido a possíveis problemas de abastecimento entre outros. 
Ao priorizar os problemas fez-se uso de outra ferramenta da qualidade, o Ishikawa, conhecido como Diagrama de Causa e Efeito que torna-se alicerce no momento de estudar esses problemas e entender as razões pelos quais acontecem. "O Diagrama de Causa e Efeito, também conhecido como Ihikawa ou Diagrama de Espinha de Peixe, é uma ferramenta de representação de possíveis causas que levam a um determinado efeito" (Leusin; 2010; p.106). A partir do uso desta ferramenta identificou-se alguns impasses, sendo um deles voltado para método, o qual deu-se maior ênfase para a criação da proposta de melhoria. O método representa a deficiência no layout o qual envolve falta de padronização no processo devido ao desarranjo dos insumos somado aos demais problemas não priorizados acarretando em perda de materiais e consequentemente elevando os custos.

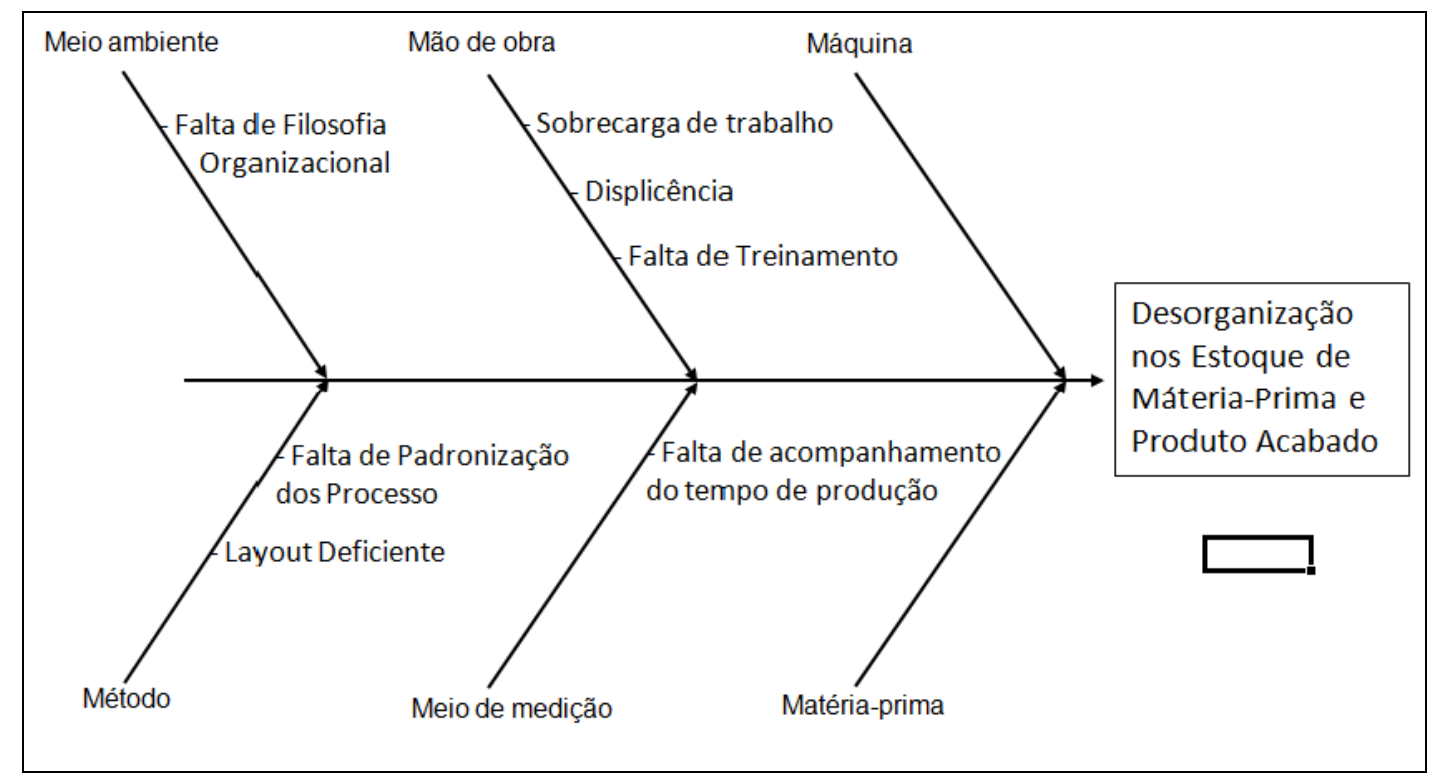

Figura 3: Diagrama de Ishikawa

Fonte: Dos próprios autores

\subsection{Análise dos Processos - Tecnologia da Informação}

Após análise do layout, verificou-se que há uma lacuna nos processos de atualização e lançamento de dados em Sistema ERP, como por exemplo, matériaprima e expedição. Devido a essa irregularidade, há deficiência em obter informações reais, o que irá refletir negativamente em todo o processo de produção e dificultar a tomada de decisões do gestor. 
A omissão de dados gera transtornos como retrabalho e investimento indevido além de desconhecer a real demanda para determinado produto. De acordo com Mañas (1999), "o sistema de informação tendo os dados atualizados, auxilia na tomada de decisões, agilidade e flexibilidade nos processos da empresa, permitindo maior competência na concorrência". Outro fator que será objeto de atenção por parte é a questão da acuracidade da informação, onde dever haver a compatibilidade entre estoque físico e estoque lógico, ou seja, virtual, no sistema. Ambos devem obter os mesmos valores. Sabe-se que este é um fator importante que traz certa qualidade nas informações que são tratadas no processo. Para Corrêa (2013), "qualquer nível de falta de acurácia trará a operação do sistema um nível adicional de incerteza".

Tratando-se de produção e faturamento, atualmente um lote de Cera líquida é faturado por $R \$ 1.600,00$, logo os 30 minutos de perda contabilizam $R \$ 200,00$ por lote. Foi estabelecida a capacidade produtiva em $70 \%$ da carga horária mensal, o que totaliza um faturamento mensal de $\mathrm{R} \$ 47.040,00$ e uma perda por desorganização o qual totaliza $R \$ 5.880,00$, significando $12,5 \%$ do faturamento.

Pensando em uma meta possível e facilmente alcançável, estabeleceu-se a redução de aproximadamente $2,5 \%$ ao mês nos 3 primeiros meses de implantação chegando ao máximo de $5 \%$ em perda, o que resultaria em um ganho de $R \$ 1.176,00$ no primeiro mês, $R \$ 2.352,00$ no segundo mês e $R \$ 3.528,00$ no terceiro mês, ilustrado conforme a figura 4 abaixo: 


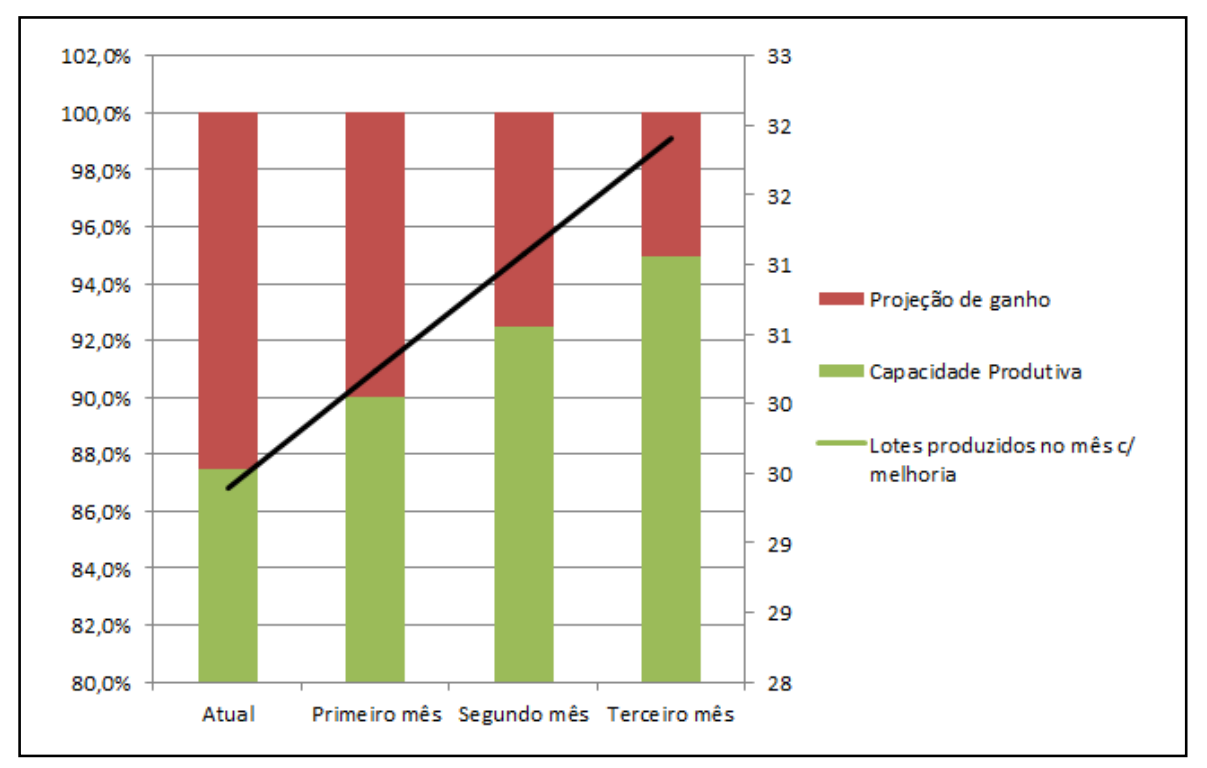

Figura 4: Gráfico de retorno

Fonte: Dos próprios autores

Em relação ao Sistema de Informação, a utilização do mesmo será viável apenas após o arranjo correto do layout. O Sistema de Informação Gestor Total é um ERP (Enterprise Resource Planning) considerado adequado para a a empresa, pois é indicado para pequenas e médias empresas, possui cadastro de clientes e fornecedores, administração de estoque, custos e controle de nota fiscal. Este sistema dá suporte para todas as operações executadas na organização o que viabiliza a total Gestão de Cadeia de suprimentos (Supply Chain Management) com ferramentas já contidas no software.

Após organização do layout, o sistema ERP ganhará mais precisão em suas atribuições em que mostrará o cenário atual da produção por intermédio da manipulação correta de dados inseridos no sistema. As avaliações dos processos podem ser feitas por meio de geração de relatórios gerados semanalmente como Indicadores Chave de desempenho (KPI) da organização, facilitando o Planejamento e Programação e Controle da Produção (PPCP). 


\section{Proposta de Melhoria}

A fim de evitar perda de tempo no processo devido à procura dos insumos e distância dos mesmos em relação à área produtiva, optou-se por construir prateleiras de alvenaria a partir de duas colunas que já havia em frente aos tanques de produção. A construção dessas prateleiras reflete diretamente na redução de tempo, pois, além dos produtos serem armazenados em ordem, eles estarão mais próximos das ferramentas utilizadas para pesagem, medição e produção final. Essas medidas serão colocadas em prática após a implantação do sistema de sinalização Kanban que auxilia o planejamento de produção e o controle de estoques. "O Kanban é um importante elemento do Sistema Toyota de Produção, sistema este que visa a eliminação total das perdas, entretanto, não são sinônimos, sendo o Kanban uma técnica para ajudar a implementar esses princípios" (Filho, João Severo; 2006; p.92).

Toda a reestruturação realizada durante e após o processo de melhoria será descrito detalhadamente no documento de Procedimento Operacional Padrão (POP). "Os Procedimentos Operacionais Padrão (POPs) são instruções detalhadas descritas para alcançar a uniformidade na execução de uma função específica” (SCIELO; 2011).

Por fim, a metodologia 5s será aplicada como uma espécie de treinamento com o objetivo de reforçar a melhoria e nova padronização. "A convivência com os cinco sensos leva os indivíduos a compreenderem melhor o seu papel dentro de uma organização e os torna parte da pirâmide dos resultados alcançados, fazendo nascer a consciência de que é preciso ser disciplinado mesmo quando não há cobranças" (Bitencourt; 2010). 


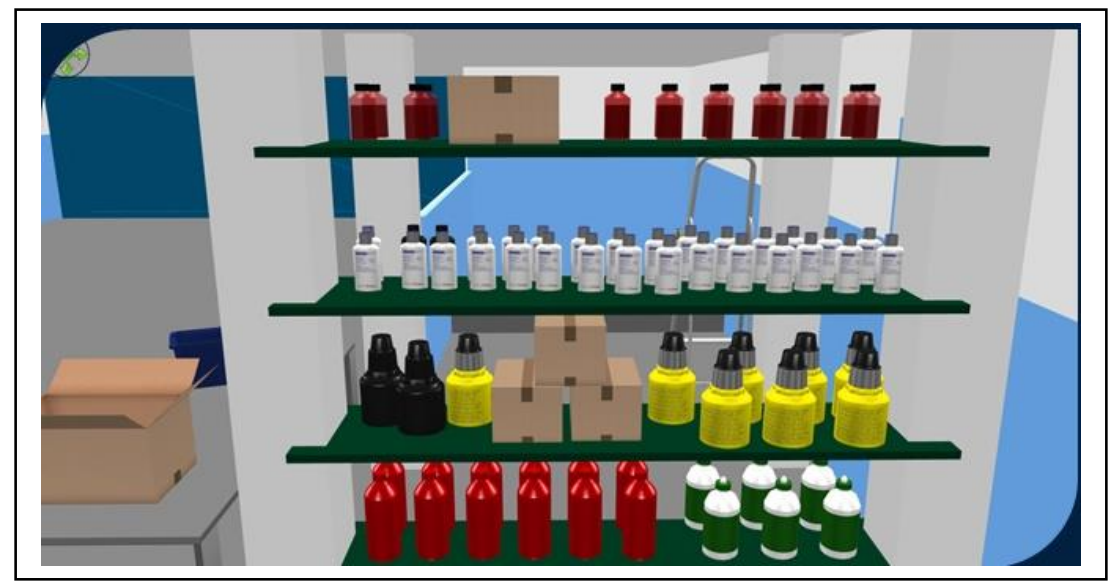

Figura 5: Prateleiras de alvenaria - novo layout Fonte: Dos próprios autores

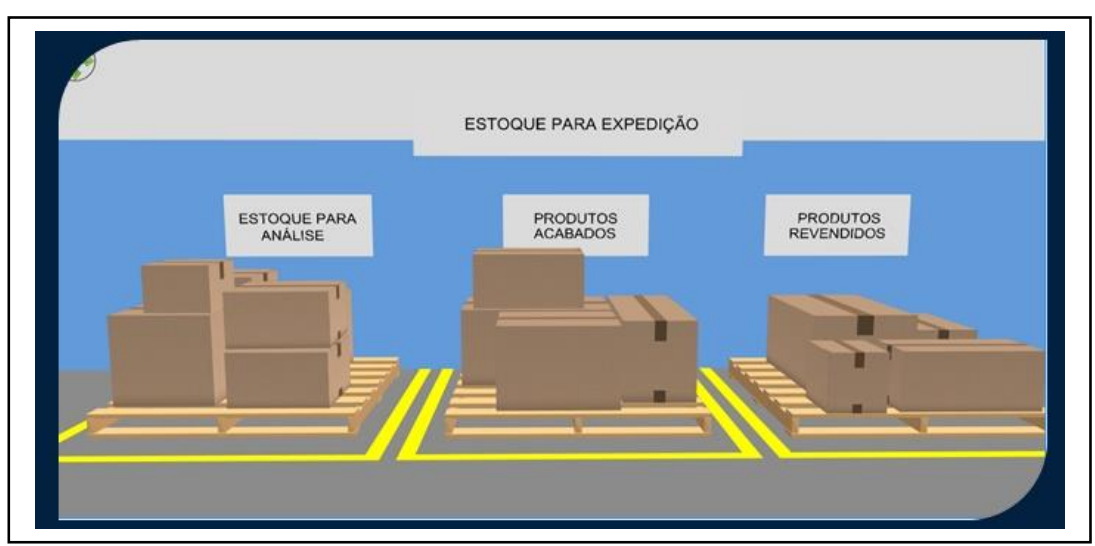

Figura 6: Estoque para expedição - novo layout Fonte: Dos próprios autores 


\section{Conclusão}

A partir da metodologia utilizada para o desenvolvimento deste projeto o qual fez-se uso de diversas análises, pesquisas em fontes fidedignas, visitas in loco e apoio nas disciplinas as quais fizeram parte da estrutura do mesmo, tornou-se possível identificar problemas reais em uma empresa real e principalmente, propor melhorias. Pode-se afirmar que após os estudos, adquiriu-se uma evolução significativa para a empresa em foco, desde o layout até o momento final do processo produtivo, o qual envolve fatores como a organização, redução de tempo e de custos.

Acredita-se que a empresa poderá usufruir de uma série de melhorias caso a mesma compreenda as análises apresentadas e acolha as propostas, à partir dos procedimentos de melhorias apresentadas. Sabe-se que uma cultura de anarquia necessitará de mudanças, transformando-se em uma cultura e ordeira. Os resultados poderão ocorrer em pequeno, médio ou em longo prazo, e dependerá da disposição e visão do gestor. Caberá a ele cobiçar a competitividade e prosperar em meio ao amplo mercado de produtos de higiene e limpeza ou manter-se estagnado e satisfeito com um negócio mediano, sem visão e sem avidez.

Conforme descrito na pesquisa, muitas oportunidades foram diagnosticadas e a atual proposta trata-se de um primeiro passo. Espera-se que esse estudo seja de fato relevante e, se aplicado conforme as orientações, o desfecho favorável seja incontestável.

"O progresso é impossível sem mudança; e aqueles que não conseguem mudar as suas mentes não conseguem mudar nada" (George B. Shaw). 


\section{Referências Bibliográficas}

ALBERTIN, A.L.; ALBERTIN, R. M. M. Tecnologia da Informação e desempenho empresarial. Atlas; 2009.

BRAVERY. Imagem Bravery. Disponível em: www.google.com.br/maps Acesso em março/2016.

BRUZZI, D. G. Gerência de Projetos. Editora SENAC, 2008.

BITENCOURT, C. O que é a metodologia 5 s e como ela é utilizada. Disponível em: www.sobreadministração.com Acesso em: junho/2016.

CLT. NR 6 - EQUIPAMENTO DE PROTEÇÃO INDIVIDUAL. Disponível em: http://www.trtsp.jus.br/geral/tribunal2/LEGIS/CLT/NRs/NR_6.html. Acesso em: Maio, 2016.

CORRÊA, H. L.; GIANESI, I. G. Planejamento, Programação e Controle da Produção. MRP II/ ERP - Conceitos, Uso e Implantação. 4 Edição, São Paulo Atlas, 2001.

CORRÊA, H. L. Administração da Produção e Operações: manufatura e serviços: uma abordagem estratégica. Atlas, 2010.

DAFT, R. L. Administração. 1.ed. Thomson; São Paulo, 2005.

ENDEAVOR. KPI - Como medir o que importa no seu negócio. Disponível em: www.endeavor.org.br Acesso em março/2016.

FILHO, J. S. Administração de Logística Integrada - Materiais, PCP e Marketing. - 2. Ed. rev. Atual; Rio de Janeiro E- papers, 2006.

IMAM, 2000. MAÑAS, A. V. Administração de Sistemas de Informação - Como otimizar a empresa por meio dos sistemas de informação. Érica; São Paulo, 1999.

LEUSIN, S. Gestão da Qualidade - 10. Ed; Rio de Janeiro FGV, 2010

MAÑAS, A. V. Administração de Sistemas de Informação - Como otimizar a empresa por meio dos sistemas de informação. Érica; São Paulo, 1999 
MANFREDINI. M. F.; SUSKI, C. A. Aplicação do Lean Manufacturing para minimização de desperdícios gerados na produção. Universidade Federal de Santa Catarina - UFSC; 2009.

MOREIRA, D. A. Administração da Produção e Operações, $2^{\circ}$ Edição revista e ampliada, São Paulo Cencage Learning, 2008.

MOURA, R.. Armazenagem: Do recebimento a expedição. IMAM, 2000.

RODRIGUES, J. N.; CARDOSO, J. F.; NUNES, C; EIRAS, R; 50 Gurus da gestão para o século XXI. $1^{\text {a }}$ Ed. Cento Atlântico, 2003.

SCIELO. POP - Procedimento Operacional Padrão. Disponível em: www.scielo.br Acesso em junho/2016 